\title{
Application of multivariable model predictive control to overcome the intervariable interaction in $\mathrm{CO}_{2}$ removal process
}

\author{
Abdul Wahid ${ }^{1,}{ }^{*}$ Fitriani Meizvira ${ }^{1}$, and Yoga Wiranoto ${ }^{1}$ \\ ${ }^{1}$ Sustainable Energy Research Group, Chemical Engineering Department, Universitas Indonesia, Depok, Indonesia
}

\begin{abstract}
Multivariable model predictive control (MMPC) was applied in $\mathrm{CO} 2$ removal process in a natural gas treatment from an industry located in Subang field, which used chemical absorption. MMPC is a variation of model predictive control (MPC) which can account for more than one control variable at once and is classified in advanced control category. MMPC is expected to give a better performance in handling the process as well as being able to overcome intervariable interaction that is prone to happen in multiple input multiple output (MIMO) system. MMPC was applied in the process to get a better process control performance compared to the one using PI controller and to make any intervariable interaction in the process more manageable. The indicator for each goal was integral square error (ISE). The result showed that identified intervariable interaction was between the pressure of gas feed in and the flow of make-up water to absorber. By using MMPC, the ISE of controller's performance was improved from the PI-controller that was used in the plant. The improvement for ISE was 32.62\% (PIC-1101) and 72.67\% (FIC-1102) in the SP tracking, and $52.54 \%$ (PIC-1101) and $57.41 \%$ (FIC-1102) in the disturbance rejection. MMPC implementation also showed a better response in handling intervariable interaction in the process.
\end{abstract}

\section{Introduction}

The amount of natural gas in Indonesia reaches 170 trillion standard cubic feet, which makes natural gas as a potential source of energy for Indonesia and can be allocated in various sections such as household, industry, and transportation [1]. With the amount of natural gas and the rising needs for energy, natural gas treatment technology should be improved continuously.

There are some treatments that need to be done before natural gas can be utilized as energy source. One of the most common and important treatment is to remove the acid gases, or is commonly called as sweetening process, from natural gas, because the existence of acid gases will damage the equipment and lower the heating value of the natural gas [2]. To ensure the process' smoothness and to give an optimal output, process control is applied to the whole process.

A type of advanced controller, multivariable model predictive control (MMPC), was used in this research as the controller used in said process. In comparison to the conventional type, proportional-integral-derivative (PI/PID) control, that is commonly used in gas industry [3-4], MMPC is expected to give a better control performance, because it can overcome any intervariable interaction that happen in a multi-input multi-output (MIMO) system [5-7]. A study of MMPC implementation in MIMO system, which was a reactive distillation column, yielded a good result in terms of intervariable interaction handling [5]. As sweetening process also requires multiple inputs and multiple outputs, the use of MMPC in sweetening process have been examined further in this research to give the process a better performance process.

Table 1. Controllers and Their Objectives

\begin{tabular}{|c|c|c|}
\hline Controller & MV & $\mathrm{CV}$ \\
\hline PIC-1101 & $\begin{array}{l}\text { Sweet gas } \\
\text { flowrate }\end{array}$ & Feed in's pressure \\
\hline LIC-1101 & $\begin{array}{l}\text { Rich amine } \\
\text { flowrate }\end{array}$ & $\begin{array}{l}\text { Liquid level in } \\
\text { absorber }\end{array}$ \\
\hline FIC-1101 & $\begin{array}{l}\text { XV-1101 } \\
\text { opening }\end{array}$ & Feed in's flowrate \\
\hline FIC-1102 & $\begin{array}{c}\text { FV-1102 } \\
\text { opening }\end{array}$ & $\begin{array}{l}\text { Make-up water's } \\
\text { flowrate }\end{array}$ \\
\hline FIC-1103 & $\begin{array}{l}\text { FV-1103 } \\
\text { opening }\end{array}$ & Amine's flowrate \\
\hline TIC-1106 & $\begin{array}{l}\text { Steam-to-HE } \\
\text { flowrate }\end{array}$ & $\begin{array}{l}\text { Amine's } \\
\text { temperature }\end{array}$ \\
\hline LIC-1104 & $\begin{array}{l}\text { Bottom output } \\
\text { flowrate in sweet } \\
\text { gas KOD }\end{array}$ & $\begin{array}{l}\text { Liquid level in } \\
\text { sweet gas KOD }\end{array}$ \\
\hline LIC-1109 & $\begin{array}{c}\text { Bottom output } \\
\text { flowrate in acid } \\
\text { gas KOD }\end{array}$ & $\begin{array}{l}\text { Liquid level in acid } \\
\text { gas KOD }\end{array}$ \\
\hline
\end{tabular}




\section{Methodology}

\subsection{Process Simulation}

The chemical process that became the object of this research was a $\mathrm{CO}_{2}$ removal process done in a natural gas industry, " $\mathrm{X}$ " company, located in Subang field, West Java, Indonesia. The process was a chemical absorption using absorber a-MDEA (activated methyl diethanolamine).

The $\mathrm{CO} 2$ removal process simulation carried in Subang field as shown by Figure 1. Natural gas flows to absorber, where it will be contacted with a-MDEA that flows from the upper part of the column. Aside from a-
MDEA, a stream of make-up water is also introduced to the absorber to keep the desired amine strength. Acid gas that in this case is $\mathrm{CO}_{2}$, is absorbed by a-MDEA and will exit from the bottom of the absorber and proceed to LP (low pressure) flash, where $\mathrm{CO}_{2}$ will be separated from a-MDEA. a-MDEA is circulated back to absorber, while the acid gas is going to a separator to be vented. Upper product of the absorber, sweet gas, flows to another separator before going to the next process.

Proportional-integral (PI) controllers that were already being used in Subang field determined the controlled variable $(\mathrm{CV})$ and the manipulated variable (MV) in this research. The controllers in the $\mathrm{CO} 2$ removal process in the Subang field are listed in Table 1.

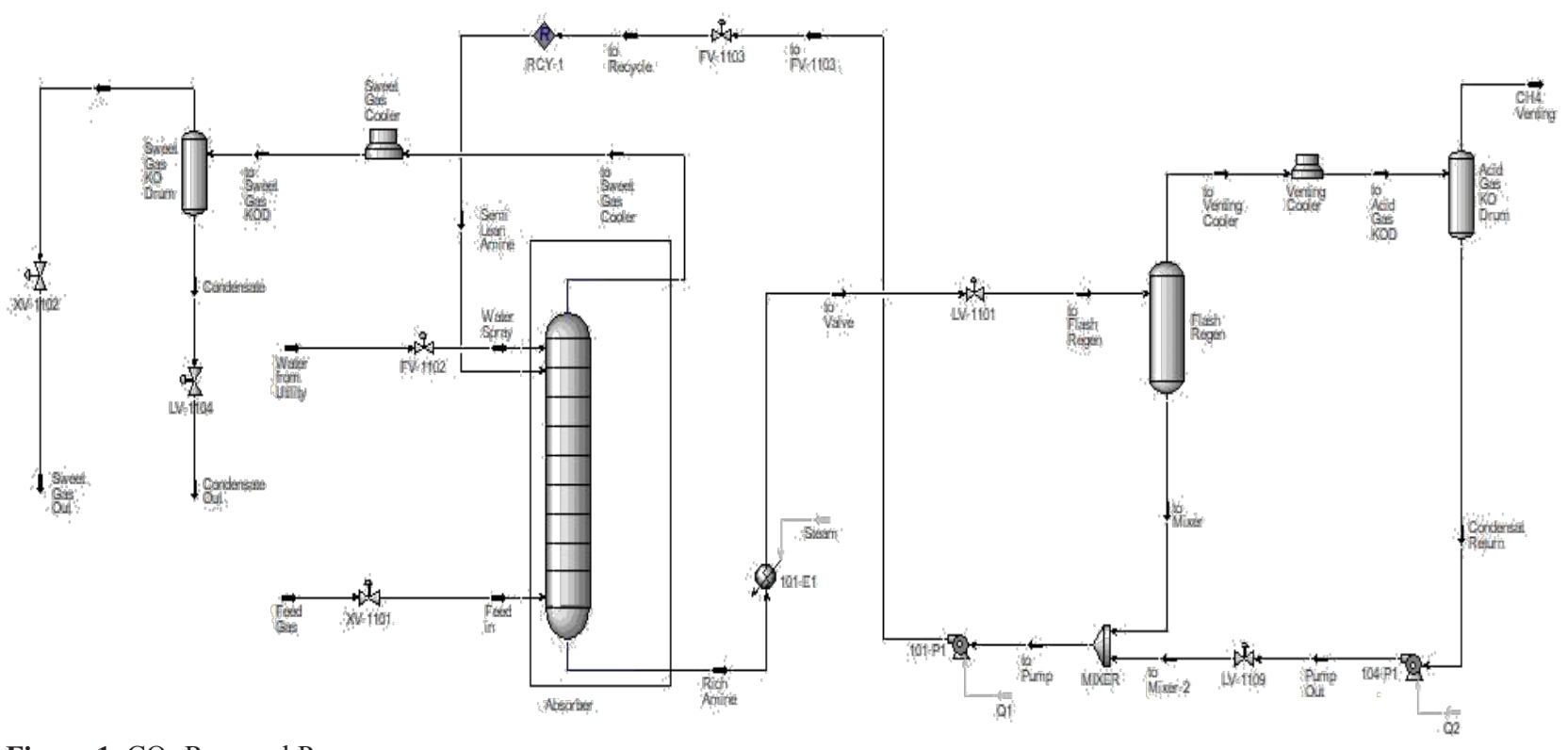

Figure 1. $\mathrm{CO}_{2}$ Removal Process

\subsection{Process Identification}

Tuning value for controllers is derived from the characteristic of the process, making process characterization an important part in controller tuning. Process characterization in this research was done by analyzing the process reaction curve (PRC). PRC is easy to construct and able to give agood visual representation to model the process in various application [8].

PRC was obtained by giving a step response to the $\mathrm{MV}$ and the value of the corresponding CV since the response until the process is back to stability, indicated by the stable value from $\mathrm{CV}$. An equation was then derived from the PRC, called first order plus dead time (FOPDT), a mathematical expression from the process that became the model of the process [9]. The standard formula for FOPDT is shown in Equation 1.

$$
G_{s}=\frac{K_{p} e^{-\theta s}}{\tau s+1}
$$

Three main components in FOPDT are $\mathrm{Kp}, \theta$, and $\tau$, which show system sensitivity, time needed by system to respond to change, and speed of the system in giving response to interference, respectively.

\subsection{Controller Tuning}

There were two tuning methods that were applied in this research: the first one was a method proposed by Shridhar and Cooper [10]. It was chosen because it was applicable for FOPDT process model and it was simple to calculate. The second method was fine tuning, through a set of trial and error, with few constraints that was taken from the same paper from Shridhar and Cooper.

The tuning parameters for MMPC are $\mathrm{P}$ (prediction horizon), $\mathrm{M}$ (control horizon), and $\mathrm{T}$ (time interval), which can be obtained using following equations:

$$
\begin{gathered}
T_{r s}=\operatorname{Max}\left(0,1 \tau_{r s} ; 0,5 \theta_{r s}\right) \\
P=N=\operatorname{Max}\left(\frac{5 \tau_{r s}}{T}+k_{r s}\right) \\
M=\operatorname{Max}=\left(\frac{\tau_{r s}}{T}+k_{r s}\right) \\
\left.k_{r s}=\left(\frac{\theta_{r s}}{T}+1\right), r=1,2, \ldots, R ; s=1,2, \ldots, S\right)
\end{gathered}
$$


While the PI controllers that were used as comparison were tuned according to the value used in the field.

\subsection{Control Performance}

To evaluate controller's performance, the system was tested with set point (SP) tracking and disturbance rejection. The tests would show how controller could manage SP alteration and regulate any disturbance introduced in the system, respectively [11]. Each controller structure was tested with SP tracking by lowering the pressure's SP from 511.3 psig to 509 psig, the lowest pressure from absorber column, and by lowering the flowrate's SP from 10.54 USGPM to 10.013 USGPM, about $5 \%$ decrease. The lowering value was associated with the cases that happened most in the industry.

The controlled system was impaired to see if the controller could return the system's condition to its desired SP or reject disturbance in case of disturbance. The disturbance given in this study was the decrease of the gas flow rate entering the absorber by 20 MMSCFD. This was determined based on conditions common to the field, where the associated company uses a gas turbine compressor to assist the flow of gas from the well, and a frequent case is if there is a disruption to the gas turbine control (GTC) engine so that the gas flow decreases.

The control performance was determined using the integral of square error (ISE) as expressed in the following equation:

$$
I S E=\int_{0}^{\infty}[S P(t)-C V(t)]^{2} d t
$$

The ISE value of MMPC would then be compared with the ISE value of PI controllers.

\section{Results and discussion}

\subsection{MIMO system}

The MMPC controller that used in this research is a $2 \times 2$ model, which meant that the controller accommodated two $\mathrm{CVs}$ and two MVs at once. To determine which variables would be controlled by the MMPC, a simple sensitivity analysis was carried out. The PI controllers were put in the simulation according to the industry's P\&ID and were set to a manual mode. Each MV was altered bychanging the corresponding valve opening. For each MV change, any significant change in a noncorresponding $\mathrm{CV}$ showed a sensitivity between variables, which showed a intervariable interaction in the process.

The sensitivity analysis yielded a result shown in Figure 2. Based on this result, the CVs are feed pressure and make-up water flow rate, while the MVs are XV1102 and FV-1102 (each's corresponding valve).
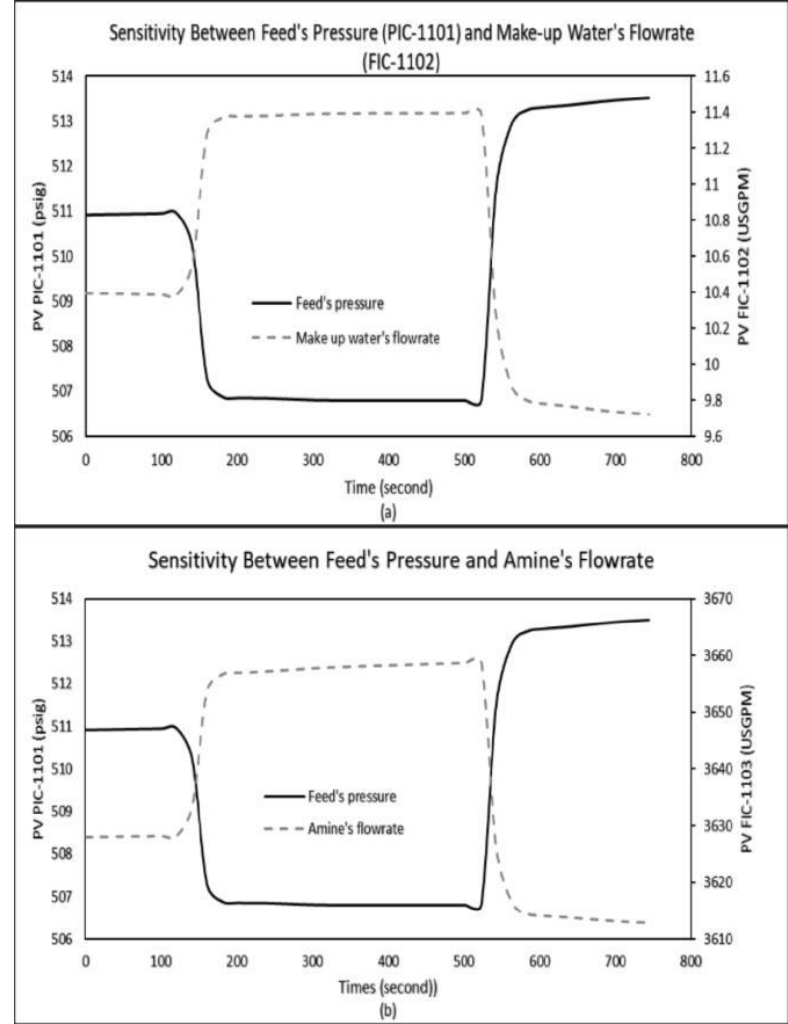

Fig. 2. Intervariable interaction between (a) feed pressure and make-up water flowrate, (b) feed pressure and amine flowrate

After determining the control object for MMPC, FOPDT for each variable combination was constructed. The FOPDT equations are provided in Table 2.

Table 2. FOPDT of MIMO System

\begin{tabular}{|c|c|c|c|}
\hline $\begin{array}{c}\text { Transfer } \\
\text { Function }\end{array}$ & CV & MV & FOPDT \\
\hline $\mathrm{G}_{1.1}$ & $\begin{array}{c}\text { Feed's } \\
\text { pressure }\end{array}$ & $\begin{array}{c}\text { XV- } \\
1102\end{array}$ & $\frac{-0,090924 e^{-0,0176665 s}}{0,0882435 s+1}$ \\
\hline $\mathrm{G}_{1.2}$ & $\begin{array}{c}\text { Feed's } \\
\text { pressure }\end{array}$ & FV-1102 & $(-)$ \\
\hline $\mathrm{G}_{2.1}$ & $\begin{array}{c}\text { Make-up } \\
\text { water's } \\
\text { flowrate }\end{array}$ & $\begin{array}{c}\mathrm{XV}- \\
1102\end{array}$ & $\frac{0,04871 e^{-0,135 s}}{0,165 s+1}$ \\
\hline $\mathrm{G}_{2.2}$ & $\begin{array}{c}\text { Make-up } \\
\text { water's } \\
\text { flowrate }\end{array}$ & $\mathrm{FV}-1102$ & $\frac{0,207 e^{-0,095 s}}{0,135 s+1}$ \\
\hline
\end{tabular}

Since there was no significant interaction between $\mathrm{CV}$ feed pressure and MV FV-1102 (originally as the MV corresponding to make-up water flowrate), the tuning tabulation proceeded with only three process models.

Table 3. Final Tuning Value

\begin{tabular}{|c|c|c|c|}
\hline \multirow{2}{*}{$\begin{array}{c}\text { Tuning } \\
\text { Method }\end{array}$} & \multicolumn{3}{|c|}{ Parameters } \\
\cline { 2 - 4 } $\begin{array}{c}\text { Shridhar } \\
\text { dan Cooper }\end{array}$ & 110 & 35 & M \\
\hline Fine tuning & 44 & 10 & 8 \\
\hline
\end{tabular}

After obtaining the FOPDT, the tuning value could be calculated by using the equations provided in point 2.3., 
and by doing a fine-tuning. The final tuning value is shown in Table 3.

The two MMPC structures were then compared to the corresponding PI controllers: feed's pressure controller (PIC-1101) and make-up water's flowrate controller (FIC-1102). Tuning value for both PI controllers are provided in Table 4.

Table 4. PI Controllers' Tuning Value in Field

\begin{tabular}{|c|c|c|}
\hline & Kc & Ti \\
\hline PIC-1101 & 7.2 & 0.768 \\
\hline FIC-1102 & 0.5 & 0.167 \\
\hline
\end{tabular}

\subsection{Set Point Change Test}

MMPC controller tuned by using fine tuning method gave the best result in set point tracking, for both CVs as shown by Figure 3 and Table 5.

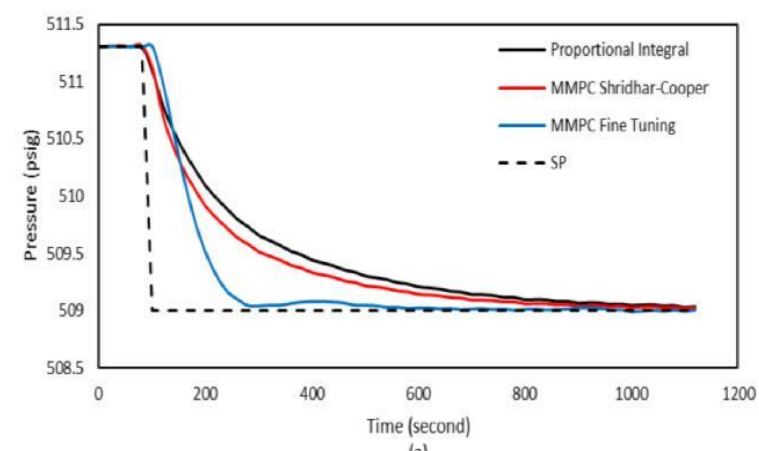

(a)

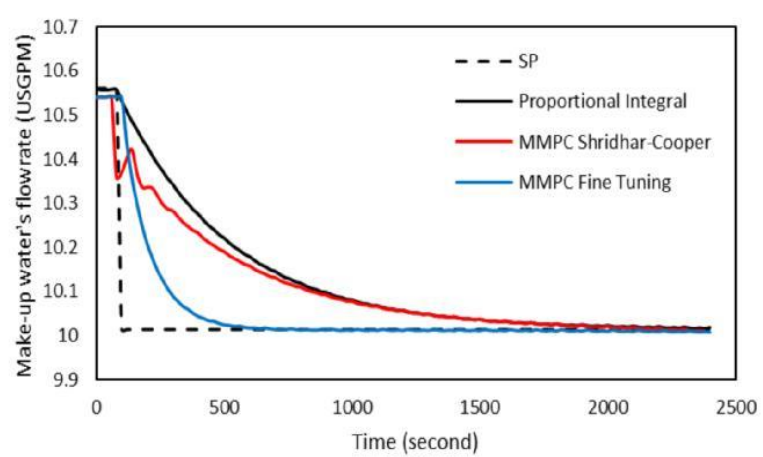

(b)

Figure 3. Set point tracking for (a) feed pressure control (b) make-up water flowrate control

Table 5. Control performance (ISE) of SP tracking

\begin{tabular}{|c|c|c|c|}
\hline $\begin{array}{c}\text { Cont- } \\
\text { roller }\end{array}$ & PI & $\begin{array}{c}\text { MMPC } \\
\text { Shridhar- } \\
\text { Cooper }\end{array}$ & $\begin{array}{c}\text { MMPC Fine } \\
\text { tuning }\end{array}$ \\
\hline $\begin{array}{c}\text { Feed's } \\
\text { pressure }\end{array}$ & 20.7 & 16.34 & 13.95 \\
\hline $\begin{array}{c}\text { Make-up } \\
\text { water's } \\
\text { flowrate }\end{array}$ & 3.07 & 2.15 & 0.84 \\
\hline
\end{tabular}

The CVs reached the desired SP faster than both PI controller and MMPC tuned by Shridhar-Cooper method and gave a relatively stable value throughout the evaluated time. It is also to be noted that MMPC that was tuned using Shridhar-Cooper method gave a slightly better performance than PI controller, judging from the ISE values. Overall, MMPC-fine tuning provides smallest ISE values among the three scenarios. Most importantly, it gave better performance than the one with PI controllers that were used in the field, with a control performance improvement of 32.62\% (PIC-1101) and $72.67 \%$ (FIC-1102), indicated from the ISE values.

\subsection{Disturbance Change Test}

Disturbance rejection using MMPC works well as shown in Figure 4 and Table 6. MMPC-fine tuning has the smallest overshoot value. In the pressure control, the difference of settling time for the three is not too big, but MMPC-fine tuning is faster to achieve the SP than other controllers, with little oscillation in the beginning. MMPC-fine tuning provides smaller ISE values than the PI controller used in the field, with a control performance improvement of $52.54 \%$ (PIC-1101) and 57.41\% (FIC1102). As for flow rate control (FIC-1102), MMPC-fine tuning also takes the shortest time to reach the SP value, at about 10.54 USGPM.
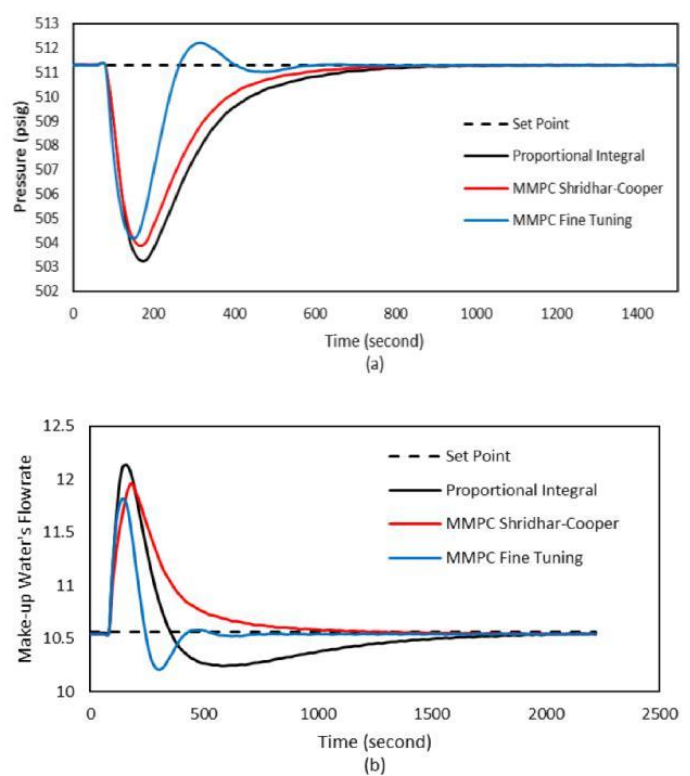

Figure 4. Disturbance rejection test for (a) feed pressure (b) make-up water's flowrate

Table 6. Control performance (ISE) of disturbance rejection

\begin{tabular}{|c|c|c|c|}
\hline Controller & PI & MMPC & MMPC \\
\cline { 3 - 4 } & & Shridhar-Cooper & Fine tuning \\
\hline $\begin{array}{c}\text { Feed's } \\
\text { pressure }\end{array}$ & 453 & 342 & 215 \\
\hline $\begin{array}{c}\text { Make-up } \\
\text { water's } \\
\text { flowrate }\end{array}$ & 16.0 & 14.5 & 6.8 \\
\hline
\end{tabular}

The phenomenon that occurs for all three control structures is the presence of overshoots, with the smallest overshoot values present in MMPC-fine tuning. Oscillation occurs in MMPC-fine tuning, but the intensity is not large and still within the $+/-5 \%$ limit of 
the specified SP. The field controller has the greatest overshoot value and the time to reach the SP is the longest. MMPC Shridhar-Cooper has an overshoot that is also not too big, but the time to reach SP is longer than MMPC-fine tuning resulting in smaller ISE values for MMPC Shridhar-Cooper.

\subsection{Intervariable Interaction Handling}

One of the advantages from MMPC is able to handle any intervariable interaction in the process, where a $\mathrm{CV}$ value changes because a changing $\mathrm{MV}$ that is not corresponding to the said CV. Graphic that showed how MMPC fine tuning gave a good intervariable interaction handling is shown in Figure 5, where the flowrate did not jump too high from the SP, and it needed the shortest time to get back to the desired SP.

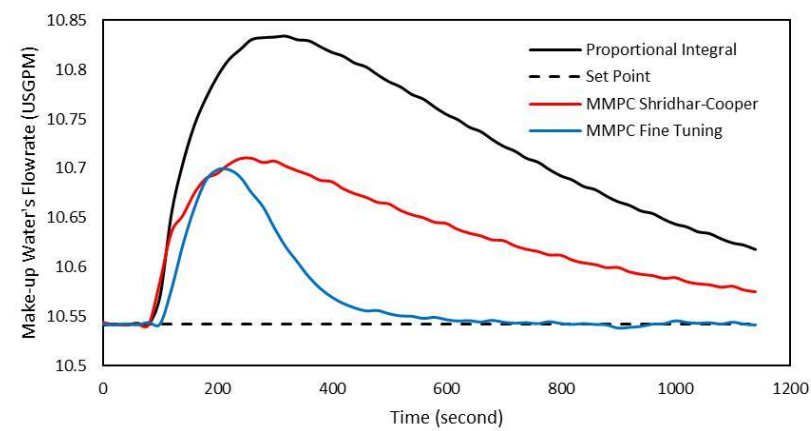

Figure 5. Intervariable interaction between feed pressure and make-up water flowrate

The other controllers did not manage to keep the error value in flowrate as small as MMPC fine tuning did.

\section{Conclusions}

MMPC gave a better process control performance compared to the PI controllers that were used in the field. The indicator used was integral square error (ISE), with the improvement for ISE was $32.62 \%$ (pressure control) and $72.67 \%$ (make-up water's flowrate control) in the SP tracking, and 52.54\% (pressure control) and 57.41\% (make-up water's flowrate control) in the disturbance rejection. MMPC implementation also showed a better response in handling intervariable interaction in the process.

We express our gratitude to the Universitas Indonesia which has funded this research through the scheme of Hibah Publikasi Internasional Terindeks untuk Tugas Akhir Mahasiswa (PITTA) No.2359/UN2.R3.1/ HKP.05.00/2018

\section{References}

1. Syukur, M. H. (2016). Potensi Gas Alam di Indonesia. Forum Teknologi.
2. S. Mokhatab, W. A. Poe, \& J. G. Speight (2006). Handbook of Natural Gas Transmission and Processing. Oxford: Elsevier Inc.

3. Astrom, K.J., Hagglund, T., Hang, C.C., and Ho, W.K. (1993). Automatic tuning and adaptation for PID controllers - a survey. Cont. Eng. Practice, 1, 699-714.

4. Kano M and Ogawa M 2010 The state of the art in chemical process control in Japan: Good practice and questionnaire survey $J$. Process Contr. 20 969-982.

5. A Wahid and I G E P Putra. Multivariable Model Predictive Control Design of Reactive Distillation Column for Dimethyl Ether Production. IOP Conf. Series: Materials Science and Engineering 334 (2018) 012018

6. A. Wahid and A. Ahmad (2015). Min-max controller output configuration to improve multi-model predictive control when dealing with disturbance rejection. International Journal of Technology. 6(3): 504-515

7. A. Wahid and A. Ahmad (2016). Improved multi-model predictive control to reject very large disturbances on a distillation column. International Journal of Technology. 6: 962-971

8. T. E. Marlin (2000). Process Control: Designing Processes and Control Systems for Dynamic Performance. United States: McGraw-Hill Higher Education.

9. C. A. Smith and A. B. Corripio (1997) Principles and Practice of Automatic Process Control. (New York: John Wiley \& Sons Inc.)

10. R. Shridhar \& D. J. Cooper (1998). A Tuning Startegy for Unconstrained Multivariable Model Predictive Control. Control Engineering Practice, 37, 4003 4016.

11. W. Tan, H. J. Marquez \& T. Chen (2004). Performance assessment of PID controllers. Control and Intelligent System, 32(3), 158166. 